\title{
The probability of ruin in a reinsurance risk model with m-dependence assumptions
}

\section{HOANG NGUYEN HUY ${ }^{1}$ and NGUYEN CHUNG ${ }^{2}$}

${ }^{1}$ University of Finance and Maketing

${ }^{2}$ University of Technical Education in Hung Yen

October 1, 2021

\begin{abstract}
In this article, we investigate a discrete-time risk model. The risk model includes the quota- $(\alpha, \beta)$ reinsurance contract effect on the surplus process. The premium process and claim process are assumed to be m-dependent sequences of i.i.d. nonnegative random variables. Using Martingale and inductive methods, we obtain upper bounds for ultimate ruin probability of an insurance company. Finally, we present a numerical example to show the efficiency of the methods.
\end{abstract}

\section{Hosted file}

Chung 23.9.2021.pdf available at https://authorea.com/users/438985/articles/540028-theprobability-of-ruin-in-a-reinsurance-risk-model-with-m-dependence-assumptions 